\title{
Endoscopic bilateral stenting of malignant hilar bile duct obstruction using novel partially covered self-expandable metal stents
}

Endoscopic bilateral stenting using conventional metal stents is considered to be technically difficult in patients with malignant hilar bile duct obstruction because the second stent is not easily inserted through the cell of the first stent wall in the bile duct [1]. A variety of new self-expandable metal stents (SEMS) specially designed for stent-in-stent procedures to facilitate bilateral stents deployment have been recently reported $[1-5]$. We report two cases of malignant hilar bile duct obstruction which were managed by endoscopic bilateral stenting using novel metal stents (KEY stents; S\&G BioTech Inc., Seongnam, Korea). These stents are self-expanding Nitinol stents partially covered with a silicone membrane and consisting of a body stent (first stent) and a limb stent (second stent). The body stent is composed of a body and two legs: a long leg and a short leg. The short leg facilitates insertion of a guide wire into the contralateral intrahepatic bile duct (IHD) for the limb stent ( $\bullet$ Fig. 1). After placement of the body stent to one side of both IHDs across the hilar stricture, the limb stent is introduced into another IHD through the short leg of the body stent ( $\bullet$ Fig. 2 ).

We successfully carried out endoscopic bilateral stenting using these stents in two patients with malignant hilar bile duct obstruction without early complications. One patient had gallbladder cancer with invasion of the hilar bile duct ( Fig.3) and the other had colon cancer with liver and hilar bile duct metastases ( Fig.4). The novel stents have some advantages in the palliative management of malignant hilar bile duct obstruction: The second stent can be easily inserted into the contralateral IHD through the opening of the short leg after the insertion of the first stent; and the central part of the stents are covered by a membrane to prevent tumor ingrowth. However, there are also

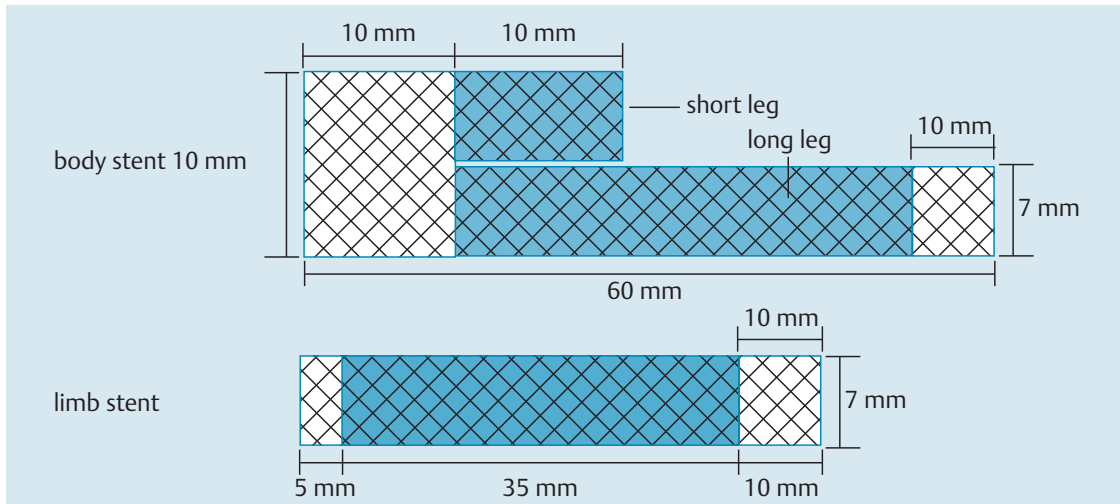

Fig. 1 Schema of the novel partially covered metal stents consisting of body and limb stents. Each stent has central silicone-covered area.

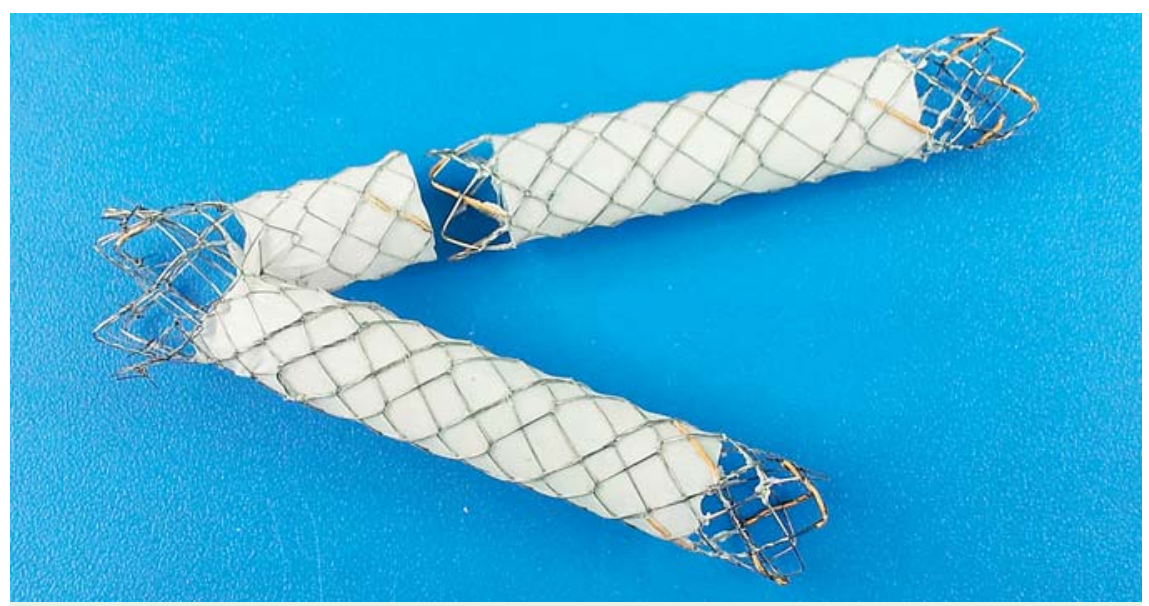

Fig. 2 The biliary self-expandable metal stent (SEMS). The limb stent (top right) can be introduced through the opening of the short leg of the body stent.

some limitations to the use of these stents. First, they have to be tailored to the extent of the stricture in each individual patient. Second, it is difficult to use them in patients with advanced malignant hilar biliary obstruction in which numerous branches are occluded. Finally, it is difficult to make the short leg of the first stent to face in the direction of the contralateral IHD during the insertion of the first stent.
In conclusion, endoscopic bilateral stent placement using the novel partially covered SEMS may be a useful treatment option in malignant obstruction of the hilar bile duct.

Endoscopy_UCTN_Code_TTT_1AR_2AZ

Competing interests: None 


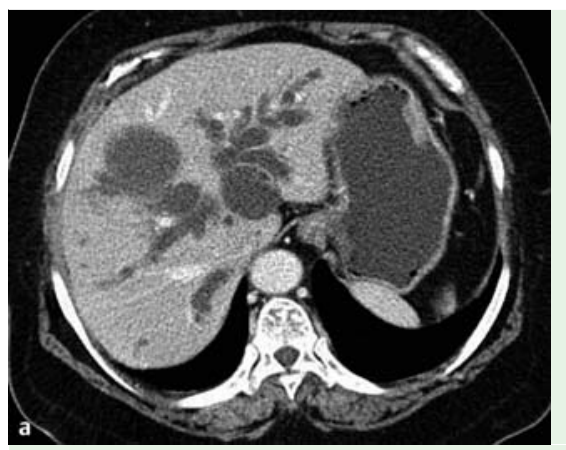

Fig. 3 a Abdominal computed tomography (CT) showing gallbladder cancer with direct invasion of liver and Bismuth type II hilar bile duct obstruction. b Endoscopic bilateral stent-in-stent placement of novel metallic stents.
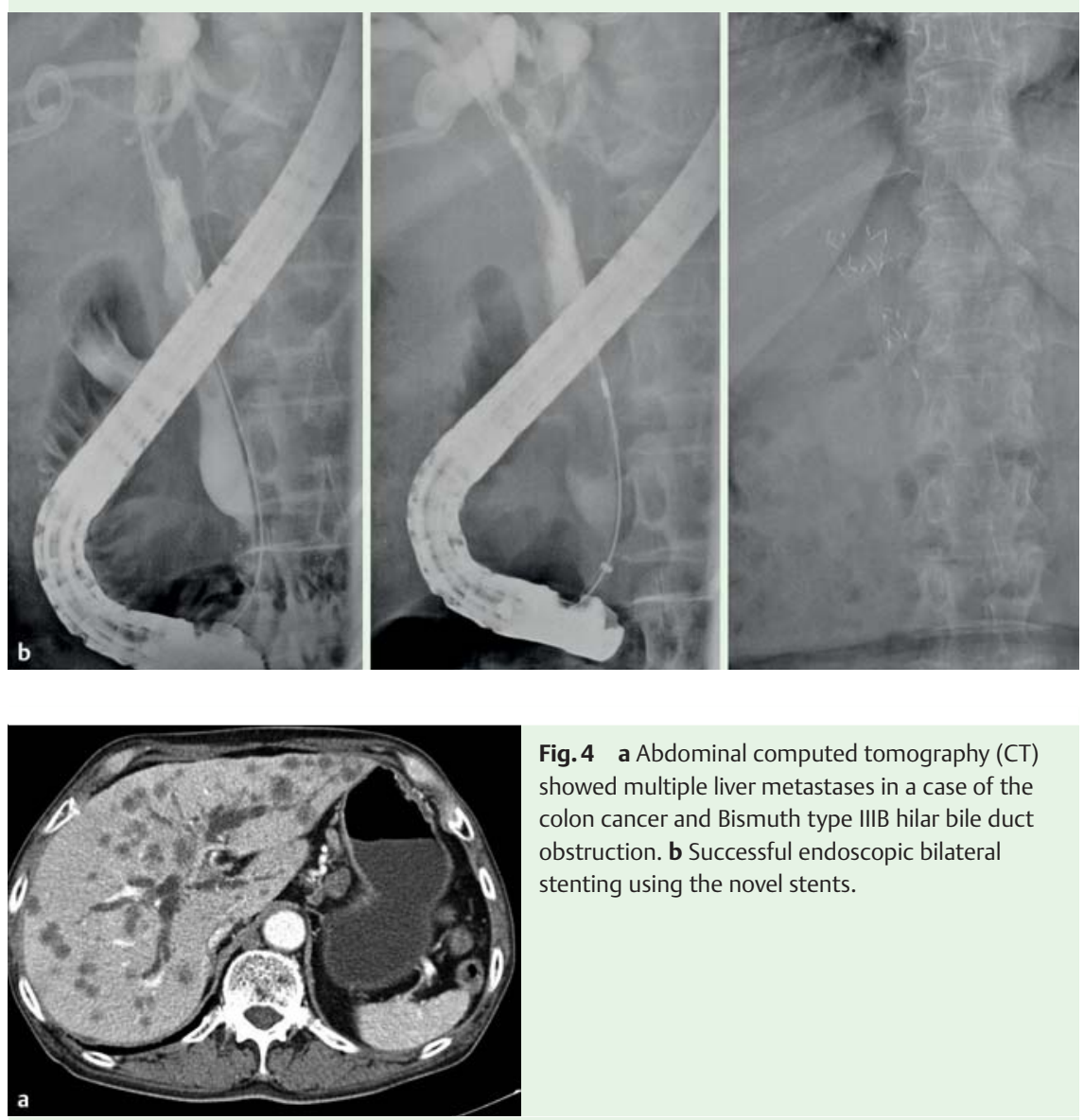

Fig. 4 a Abdominal computed tomography (CT) showed multiple liver metastases in a case of the colon cancer and Bismuth type IIIB hilar bile duct obstruction. b Successful endoscopic bilateral stenting using the novel stents.
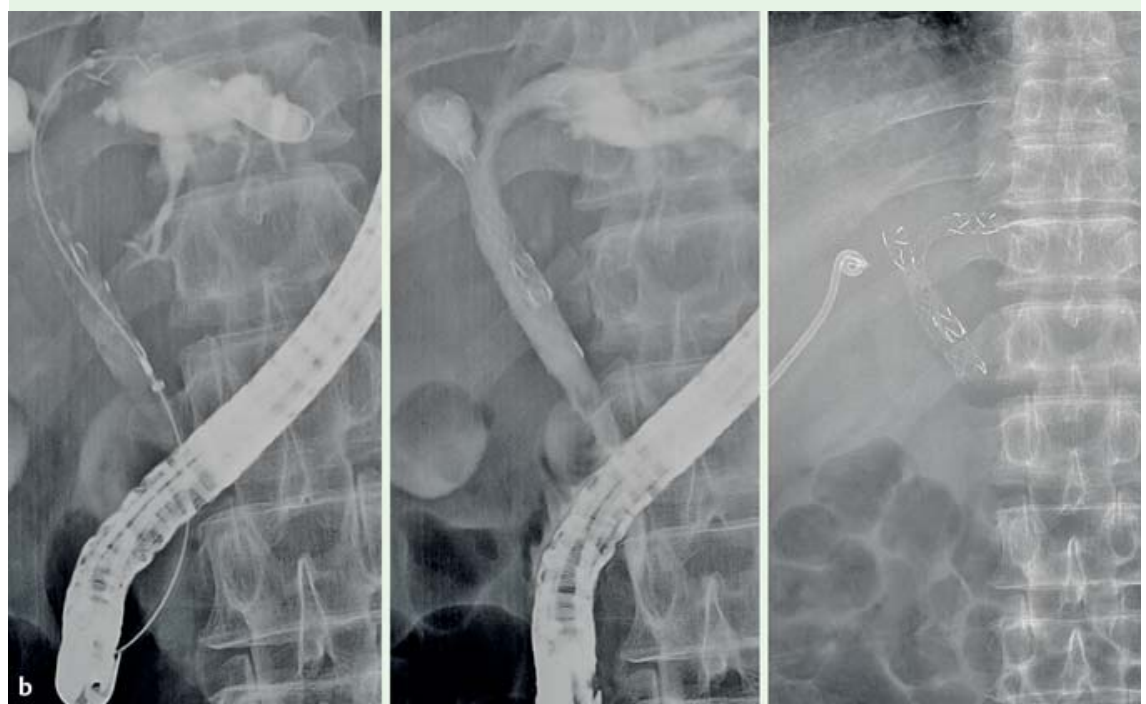

\section{S. S. Yoo ${ }^{1}$, S. Jeong ${ }^{2}$, D. H. Lee ${ }^{2}$}

${ }^{1}$ Division of Gastroenterology, Samsung Medical Center, Sungkyunkwan University School of Medicine, Seoul, South Korea

${ }^{2}$ Division of Gastroenterology, Department of Internal Medicine, Inha University School of Medicine, Incheon, South Korea

\section{References}

1 Hwang JC, Kim JH, Lim SG et al. Y-shaped endoscopic bilateral metal stent placement for malignant hilar biliary obstruction: prospective long-term study. Scand J Gastroenterol 2011; 46: 326-372

2 Lee JH, Kang DH, Kim JY et al. Endoscopic bilateral metal stent placement for advanced hilar cholangiocarcinoma: a pilot study of a newly designed Y stent. Gastrointest Endosc 2007; 66: 364-369

$3 \mathrm{Kim}$ JY, Kang DH, Kim HW et al. Usefulness of slimmer and open-cell-design stents for endoscopic bilateral stenting and endoscopic revision in patients with hilar cholangiocarcinoma (with video). Gastrointest Endosc 2009; 70: 1109-1115

4 Kanno $Y$, Ito K, Fujita $N$ et al. Single-session endoscopic bilateral Y-configured placement of metal stents for hilar malignant biliary obstruction. Dig Endosc 2011; 23: 91 96

5 Park DH, Lee SS, Moon JH et al. Newly designed stent for endoscopic bilateral stent-in-stent placement of metallic stents in patients with malignant hilar biliary strictures: multicenter prospective feasibility study (with videos). Gastrointest Endosc 2009; 69: 1357-1360

\section{Bibliography}

DOI http://dx.doi.org/

10.1055/s-0032-1326122

Endoscopy 2013; 45: E328-E329

(c) Georg Thieme Verlag KG

Stuttgart · New York

ISSN 0013-726X

Corresponding author

S. Jeong

Division of Gastroenterology

Department of Internal Medicine

Inha University Hospital

7-206, 3-Ga, Sinheung-Dong

Jung-Gu, Incheon 400-711

South Korea

Fax: +82-32-8902549

inos@inha.ac.kr 